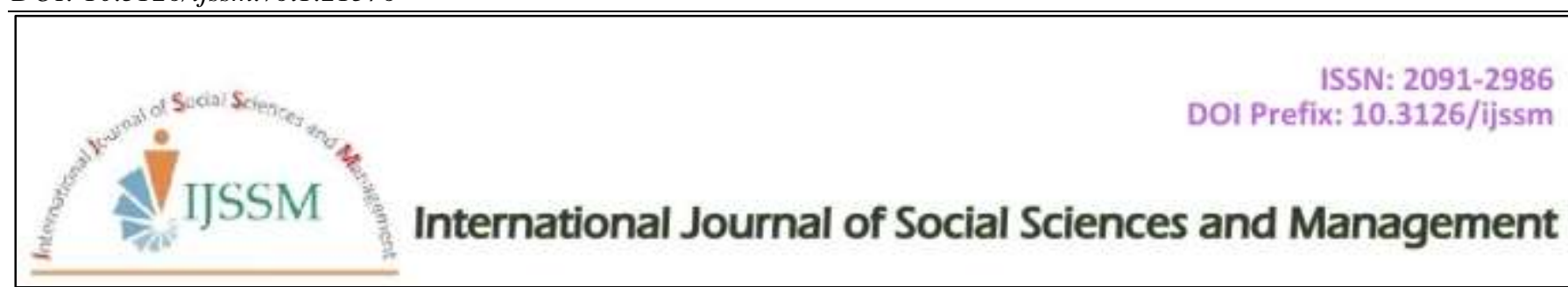

Research Article

\title{
Knowledge, Attitudes and Beliefs Regarding Drug Abuse among Male of Rural Community, Lahore, Pakistan
}

\author{
Orung Zaib Masih $^{1 *}$, Muhammad Hussain ${ }^{1}$, Muhammad Afzal ${ }^{1}$, Safina Emanual ${ }^{1}$ \\ Lahore school of Nursing, University of Lahore, Pakistan
}

\begin{abstract}
Substance mishandle in Pakistan is one of the real reasons for worry that influences all sections of society. It has not just destroying consequences for the physical and mental prosperity yet in addition has the unfriendly impacts on labor and financial development of the nation. Roughly 6.7S million peoples in Pakistan have been related with various sorts of prescriptions. For instance, Cannabis is the most frequently used solution, with an inescapability of $3.6 \%$ of the people, after that poly-calm use is ordinary. With reference to sedatives, a normal 860,000 masses are general heroin customers and 320,000 are opium.

Methods: The quantitative cross sectional study was used.

Results: The discoveries of the examination. in 23 tables and 27 figures have been utilized to demonstrate comes about. That just about 80 for every penny of respondents viewed every single illicit medication as similarly hurtful to one's wellbeing recommend an inability to perceive the distinctive different impacts related with various medication writes (Cocaine, Grass, and Heroin). More than 94 for every penny of respondents announced that they had known about cannabis, and the larger part of respondents detailed having known about bliss $(96.3 \%)$, cocaine $(96.4 \%)$ and heroin $(92.3 \%)$.
\end{abstract}

Conclusions: The knowledge, attitude, and beliefs of drug abuse among male are good.

Keywords: Drug Abuse; Community; Men; Knowledge; Attitude; Beliefs

\section{Introduction}

Substance abuse in Pakistan is one of the real foundations for worry that influences all sections of society. It has not just destroying consequences for the physical and mental prosperity yet additionally has the antagonistic impacts on labor and financial development of the nation. It is generally trusted that, in Pakistan, among the real open, social and restorative issues of the twentieth century, drug abuse positions as a standout amongst the most destroying and expensive (Aslam, 2015).

\section{Cite this article as:}

O.Z. Masih et al. (2019) Int. J. Soc. Sc. Manage. Vol. 6, Issue-1: 1-6. DOI: 10.3126/ijssm.v6i1.21576

1 ,*Corresponding author

Orung Zaib Masih,

Lahore school of Nursing, University of Lahore, Pakistan

Email: zaibgouri@gmail.com

Peer reviewed under authority of IJSSM

(C) 2019 International Journal of Social Sciences and Management

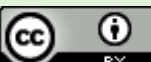

This is an open access article \& it is licensed under a Creative Commons Attribution 4.0 International License (https://creativecommons.org/licenses/by/4.0/) 
Drug abuse is a sort of synthetic which impact and cause change in human personality by driving condition of inebriation. There is different sort of substance which is usually utilized by the general population. It is conceivable to arrange it substance is lawful or illicit .Moreover there are distinctive substance recorded by WHO and which are utilize wrongfully as cerebrum depressant and impact the clients contrarily like, opioids, cannabis, cocaine ,stimulants, inhalants etc .Illegal substance is harmful to the point that nations over the world have been attempting to control them (Sungu, 2015).

The Public attitudes towards the drug issue are huge on the grounds that it is dubious whether tranquilize related approaches will at last prevail without the sponsorship (the beliefs and support) of general society.

This sponsorship is reliant upon, interalia, the exactness of people in general's drug related knowledge and the ideas of the general population's states of mind towards tranquilize clients. The exactness of people in general's medication related learning is critical on the grounds that wrong data may impact the overall population to help tranquilize strategies in light of invalid suspicions (Keene, 1997).

The general population's attitudes towards drug users are imperative in that it has been recommended that the restoration and re-incorporation of drug dependent people into standard society can't be accomplished until the point that societal dispositions are certain and tolerating.

During study examined towards public's attitudes decriminalization of 'delicate' and 'hard' drug, sedate instruction and mischief decrease training. Notwithstanding the way that drug was normally viewed as a critical issue, a sizeable minority of respondents, especially more youthful individuals, supported some type of drug sanctioning or decriminalization. Support for sedate instruction was practically consistent, and was especially invited for those matured in the vicinity conventional preventive training methodologies. States of mind to sedate utilize may likewise depend to some degree on social gathering participation and the mentalities held by the social gathering all in all. An affiliation has additionally been found amongst sex and period of medication related mischief, with ladies seeing medication use as far more dangerous than men (Leitner et al., 1993).

In the UK, it has been assessed that around 4 million individuals utilize illegal medications every year, with cannabis by a long shot the most normally utilized, trailed by cocaine and rapture (Simpson \& McNulty, 2008).

As a standout amongst the most well-known addictions sorts, substance dependence is considered as cerebrum illness due to substances effects on mind. These impacts could be dependable, and might prompt hurtful practices found in the general population who drug abuse (NIDA, 2007).

Early examinations on substance abuse and dependence misconstrued these ideas and individuals who utilized medications were believed to be somewhat ethically damaged and need assurance, so they were not ready to control their practices. Similarly, individuals saw drugs use as a sort of good disappointment instead of medical issue. However logical inquiries demonstrated that addictions must be viewed as a sort of infections affecting both mind and human conduct(Volkow, Fowler, Wang, Swanson, \& Telang, 2007).

Drug abuse is characterized as the utilization of a substance for a reason not predictable with lawful or medicinal rules (WHO, 2006).

It negatively affects wellbeing or working and may appear as medication reliance, or be a piece of a more extensive range of tricky or destructive conduct (DH, 2006b).

Drug abuse and reliance, has broken out of very much characterized confined someone who is addicted groups and advanced into a worldwide issue which penetrates all strata of society(Dos Santos, 2006).

\section{Aims of The Study}

The aim of this study was to assess the level of knowledge, attitude and beliefs regarding drug abuse of rural community Lahore.

\section{Significance of The Study}

The significance of this study is to identify the gap exist between knowledge regarding drug abuse. The result of this study will be helpful for the community administration to estimate the knowledge, attitude and beliefs of people towards the prevention of drug abuse. The awareness of male regarding drug abuse is very significant to minimize its prevalence in future. The study findings will assist the stake holders of the community to know the level of drug abuse and also help the Government/Institutes and NGO's to develop the strategies to enhance the knowledge regarding drug abuse treatment among the society to avoid the damages from the problem. Furthermore, the study finding increased the awareness among the societies regarding cure of the problem and help the policy makers in the identification of the societies which are affected by drug abuse. Similarly, the study finding shaped the positive attitude of the society member towards the prevention of the drug abuse. Thus, the current study had been helpful to enhance the knowledge and make their positive attitude \& beliefs towards the drug abuse.

This study will help the government among others to better understand the current situation and accordingly make changes to address the factors that contribute to drug abuse among our youngest. Through the study give the knowledge; assess the attitude and beliefs of population 
related drug abuse in community and give the awareness about drug abuse complication and disadvantages.

Through this examination examples and polices ' which impact the levels and examples of substance utilize and related mischief can essentially lessen for provincial group, the general medical issues owing to substance utilize, and intercessions at the social insurance framework level can work towards the rebuilding of wellbeing in influenced people.

\section{Literature Review}

In Pakistan reliably no under 50,000 more people wind up clearly subject to different sorts of meds in Pakistan (http://tribune.com.pk/story/196455/day-against-drugabuse-more-than-8-1-m-addicts-in-pakistan-). The amount of solution customers in Pakistan has gone up from 50,000 out of 1980 to 6.2 million of each 2006 and 8.1 million of each 2011. It is assessed that 1 of every 27 grown-ups in Pakistan are reliant on drugs (UNODC, 2013).

The Ministry of Narcotics Control, Pakistan, the Bureau of Statistics, Pakistan, and the United Nations Office on Drugs and Crime released a group particular abstract report in 2013 on sedate use in Pakistan. This report insisted that cannabis is the medicine most for the most part used by Pakistanis developed 15 to 64 (3.6 for each penny of the people, or around four million people). Narcotic use (heroin or opium) is furthermore sweeping with one for each penny of the people (one million people) using it (Kayani et al., 2013).

The Ministry of Narcotics Control, Pakistan, the Bureau of Statistics, Pakistan, and the United Nations Office on Drugs and Crime discharged a community specialized synopsis report in 2013 on tranquilize use in Pakistan. This report affirmed that cannabis is the medication most generally utilized by Pakistanis matured 15 to 64 (3.6 for every penny of the populace, or roughly four million individuals). Sedative utilize (heroin or opium) is additionally far reaching with one for every penny of the populace (one million individuals) utilizing it ( Kayani et al., 2013).

An investigation directed in the UK, it has been assessed that around 4 million individuals utilize illegal medications every year, with cannabis by a wide margin the most usually utilized, trailed by cocaine and rapture. Opioid abuse happens on a littler scale yet is related with substantially more noteworthy rates of mischief than either cocaine or cannabis(Simpson \& McNulty, 2008).

Globally, the United Nations Office on Drugs and Crime estimates that between 155 and 250 million people (3.5 to $5.7 \%$ of the population aged 15-64) used illicit substances at least once in 2008.

Another examination directed which is all around; cannabis clients include the biggest number of unlawful medication clients (129 - 190 million individuals). Amphetamine- bunch substances rank as the second most regularly utilized illegal medication, trailed by cocaine and sedatives. At the center of medication utilization lies the issue tranquilizes users $^{\text {ee: }}$ the individuals who infuse drugs and additionally are viewed as reliant, confronting genuine social and wellbeing outcomes thus. In light of the worldwide appraisals of the quantity of cannabis, sedative, cocaine and amphetamine-type stimulants clients, it was assessed that there were in the vicinity of 16 and 38 million issue illegal medication clients on the planet in 2008. This speaks to $10 \%$ to $15 \%$ surprisingly who utilized medications that year. It can be evaluated that in 2008, comprehensively, between $12 \%$ and $30 \%$ of issue sedate clients had gotten treatment in the previous year, which implies that in the vicinity of 11 and 33.5 million issue medicate clients did not get treatment that year (United Nations Office on Drugs, Crime, 2010).

Another examination which is immediate in South Africa is going up against a gigantic augmentation in substance maul. As demonstrated by the disclosures by the South African Community Epidemiology Network on Drug Use (2010:1), cannabis is up 'til now the most broadly perceived unlawful solution used, especially among youth going to ace treatment centers. Nevertheless, in Cape Town valuable stone methamphetamine remains transcendent, and the degree of patients yielded extended in the fundamental bit of 2009. A ratty kind of heroin alluded to locally as ,,sugars ${ }^{\text {ce }}$ has ended up being ordinary in an, as it were, Indian suburb in the Durban area (Chatsworth) and $17 \%$ of patients surrendered in this period nitty gritty it as their basic substance of misuse. The degree of affirmations for cocaine remained stable in the Eastern Cape, where $8 \%$ of patient's uncovered cocaine as their basic substance of misuses.

As per World wellbeing association, 230 million individuals, or 1 of every 20 grown-ups, are assessed to have utilized an unlawful medication in any event once in 2010 .

As per the World Drug Report issued by the United Nations Office on Drugs and Crime, it is assessed that in the vicinity of 172 and 250 million people utilized medications at any rate once in the year 2007.All inclusive, the United Nations Office on Drugs and Crime gauges that in the vicinity of 155 and 250 million individuals (3.5 to $5.7 \%$ of the populace matured 15-64) utilized unlawful substances in any event once in 2008 (United Nations Office on Drugs, Crime, 2010)

\section{Conceptual Framework}

Agreeing the hypothesis of "Perceived Effects Theory" (Smith). Initiation of substance utilize relies upon accessibility; on conduct and states of mind in regards to medicate utilization of good examples and critical others"; on demeanors, convictions, and assumptions with respect to the prompt and longer term focal points and impediments of 
utilization; and on identity attributes that encourage or restrain utilize.

Demeanors and conduct with respect to substance use with respect to companions and good examples (e.g., more established kin, guardians, striking individuals from reference gatherings) impact the likelihood of start. On the off chance that utilization is polished by (or is worthy to) such "critical others," start is more probable; it is likewise more prone to happen at an early age. Albeit most starts trust that the advantages of infrequent utilize exceed its dangers, a specific start will have differed and blended mentalities, convictions, and assumptions in regards to the potential points of interest and hindrances of substance utilize. This perplexing blend of states of mind, convictions, and desires creates a net impact speaking to a general inclination that can go from amazingly positive to a great degree negative. The more positive the net impact, the higher the likelihood of start, and the prior it is probably going to happen (Fig. 1).

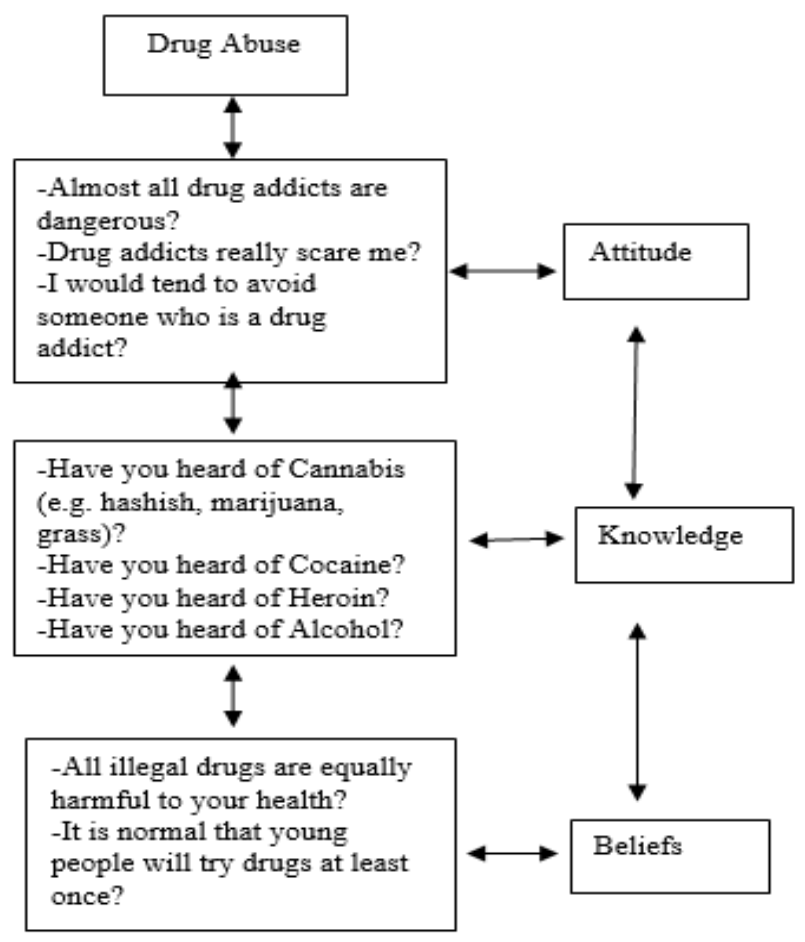

Fig. 1: Conceptual framework

\section{Methodology}

\section{Setting}

This research was conduct in the rural community Hussana Abad, Lahore, Pakistan.

\section{Research Design}

This quantitative descriptive cross-sectional study

\section{Population}

The target populations were male.

\section{Sampling}

Respondents' selection was 100 .

\section{Research Instrument}

A questionnaire was designed for this study to gather data to answer the research questions. The data collected by face to face interviews from the respondents' homes. Responded result is recorded on hard copy questionnaires.

\section{Data Gathering Procedure}

Informed to participants about the aim of the study.

\section{Methods Used to Analyze Data}

Data was analyzed by SPSS version 21. Statistical analysis for study was Descriptive Statistics.

\section{Study Duration}

Research process is complete from September,2017 t0 December,2017.

\section{Ethical Consideration}

Take the permission letter from school of nursing, university of Lahore, committee to conduct the study.

\section{Results}

This section presents the outcomes of the study.

\section{Profile of The Respondents}

Data is collected taken both private and government setup.

Data shown in Table 1 shows that a total of $100 \%$ were male. Among the respondents, the percentage of married male respondents was the highest $58.59 \%$ and the unmarried response $41.41 \%$. Education of respondent primary $35 \%$, middle $52 \%$ and matric $8.7 \%$. shows It is result that (96\%) male have known about cannabis, $(96 \%)$ male have listen of ecstasy, and (100\%)

Table 1: Demographic Information of Participants

\begin{tabular}{lll}
\hline Gender of respondents & Male (100) $100 \%$ & $(1.00 \pm .000)$ \\
Age Group of respondents & $1=15-29$ (4) $3.9 \%$ & $(1.52 \pm .502)$ \\
& $2=30-70(51) 49.5 \%$ & \\
Marital Status of respondents & $1=$ Married (58) $58.59 \%$ & $(1.41 \pm .495)$ \\
& $2=$ Unmarried (41) $41.41 . \%$ \\
Education of respondents & $1=$ Primary (36)35\% \\
& $2=$ Middle (54)52.4\% \\
& $3=$ Metric (9) 8.7 & \\
&
\end{tabular}


It is result that (94\%) male have known about cannabis, $(96 \%)$ male have listen of ecstasy, and $(100 \%)$ male have heard of heroin as shown in $(4 \%)$ personally know who someone has drug problem. Have you ever heard about Cannabis (e.g .hashish, marijuana, grass 94\% ( $n=94)$ replied yes and $6 \%(n=6)$ replied no. (Table 2).

It is result that (96\%) male have known about cannabis, $(96 \%)$ male have listen of ecstasy, and (100\%) male have heard of heroin as shown in $(4 \%)$ personally know who someone has drug problem. Table 3 shows that almost all drug addicts are dangerous about participant replied $12.00 \%$ $(\mathrm{n}=12) \quad$ strongly disagree $\quad 10.00 \% \quad(\mathrm{n}=10) \quad$ disagree moderately $6.00 \%(n=6)$ disagree slightly $8.00 \% \quad(n=8)$ don't know $27.00 \%(n=27)$ agree slightly $16.00 \%(n=16)$ agree moderately $19.00(n=19)$ agree strongly. I would tend to avoid someone who is a drug addict participant replied $4.00 \%(n=4)$ strongly disagree $3.00 \%(n=3)$ don't know $23.00 \% \quad(n=23)$ agree slightly $31.00 \%(n=31)$ agree moderately 39.00(n=39) agree strongly. Drug addict are not given a fair chance to get along in society participant replied $7.00 \%(n=7)$ strongly disagree $12.00 \%(n=12)$ disagree moderately $15.00 \%(n=15)$ disagree slightly $11.00 \%(n=11)$ agree slightly $12.00(n=12)$ agree strongly.

Table 2. Knowledge Regarding Drug Abuse

\begin{tabular}{lllll}
\hline Variable & Yes & No & D, K & M \& SD \\
\hline $\begin{array}{l}\text { Have you heard of Cannabis (e.g. } \\
\text { hashish, marijuana, grass)? }\end{array}$ & $94(94 \%)$ & $6(6 \%)$ & $0(0 \%)$ & $(1.06 \pm .239)$ \\
$\begin{array}{l}\text { Have you heard of Ecstasy (e.g. E/E } \\
\text { tablets)? }\end{array}$ & $96(96 \%)$ & $4(4 . \%)$ & $0(0 \%)$ & $(1.04 \pm .197)$ \\
$\begin{array}{l}\text { Have you heard of Heroin? } \\
\begin{array}{l}\text { I personally know who someone } \\
\text { has/had drug problem. }\end{array}\end{array}$ & $100(100 \%)$ & $0(0 \%)$ & $0(0 \%)$ & $(1.00 \pm .000)$ \\
\end{tabular}

Table. 3: Attitudes Regarding Drug Abuse

\begin{tabular}{|c|c|c|c|c|c|c|c|}
\hline Variable & 1 & 2 & 3 & 4 & 5 & 6 & 7 \\
\hline Almost all drug addicts are dangerous. & $2(1.9 \%)$ & $4(3.9 \%)$ & $\begin{array}{l}13 \\
(12.6 \%)\end{array}$ & $\begin{array}{l}54 \\
(52.4 \%)\end{array}$ & $\begin{array}{l}7 \\
(262.2 \%)\end{array}$ & $100 \%$ & $4.58 \pm 1.986$ \\
\hline $\begin{array}{l}\text { I would tend to avoid someone who is a drug } \\
\text { addict. }\end{array}$ & $\begin{array}{l}26 \\
(25.2 \%)\end{array}$ & $\begin{array}{l}74 \\
(71.8 \%)\end{array}$ & $0 \%$ & $0.0 \%$ & $0 \%$ & $100 \%$ & $1.84 \pm .300$ \\
\hline $\begin{array}{l}\text { Drug addicts are not given a fair chance to get } \\
\text { along in society. }\end{array}$ & $\begin{array}{l}17 \\
(16.5 \%)\end{array}$ & $\begin{array}{l}24 \\
(23.3 \%)\end{array}$ & $0 \%$ & $\begin{array}{l}19 \\
(18.4 \%)\end{array}$ & $\begin{array}{l}40 \\
(38.8 \%)\end{array}$ & $100 \%$ & $1.05 \pm .219$ \\
\hline $\begin{array}{l}\text { People who end up with a drugs problem have } \\
\text { only themselves to blame. }\end{array}$ & $00 \%$ & $0(0 \%)$ & $0(0 \%)$ & $6(64.1 \%)$ & $33 \%$ & $100 \%$ & $1.34 \pm .446$ \\
\hline Drug addicts really scare me & $\begin{array}{l}61 \\
(59.2 \%)\end{array}$ & $\begin{array}{l}39 \\
(37.9 \%)\end{array}$ & $0(0 \%)$ & $0(0 \%)$ & $0(0 \%)$ & $100 \%$ & $4.00 \pm .865$ \\
\hline
\end{tabular}

Table 4: Participation's Beliefs Regarding Drug Abuse

\begin{tabular}{|c|c|c|c|c|c|c|c|}
\hline Variable & 1 & 2 & 3 & 4 & 5 & 6 & 7 \\
\hline $\begin{array}{l}\text { All illegal drugs are equally } \\
\text { harmful to your health. }\end{array}$ & $\begin{array}{l}54 \\
(54 \%)\end{array}$ & $\begin{array}{l}17 \\
(17 \%)\end{array}$ & $\begin{array}{l}0 \\
(0 \%)\end{array}$ & $\begin{array}{l}29 \\
(52 \%)\end{array}$ & $\begin{array}{l}7 \\
262.2\end{array}$ & $\begin{array}{l}100 \\
100 \%\end{array}$ & $6.37 \pm .761$ \\
\hline $\begin{array}{l}\text { If you try drugs even once, you } \\
\text { are hooked. }\end{array}$ & $\begin{array}{l}2 \\
(25.2)\end{array}$ & $\begin{array}{l}74 \\
(71.8)\end{array}$ & $\begin{array}{l}0 \\
(0 \%)\end{array}$ & $\begin{array}{l}0 \\
(0 \%)\end{array}$ & $\begin{array}{l}0 \\
(0 \%)\end{array}$ & $\begin{array}{l}100 \\
(100 \%)\end{array}$ & $2.21 \pm 1.018$ \\
\hline $\begin{array}{l}\text { Occasional use of cannabis is not } \\
\text { really dangerous. }\end{array}$ & $\begin{array}{l}17 \\
(16.5 \%)\end{array}$ & $\begin{array}{l}24 \\
(23.3 \%)\end{array}$ & $\begin{array}{l}0 \\
(0 \%)\end{array}$ & $\begin{array}{l}19 \\
(18.4 \%)\end{array}$ & $\begin{array}{l}(40 \\
(38.8 \%)\end{array}$ & $\begin{array}{l}100 \\
(100 \%)\end{array}$ & $1.05 \pm .219$ \\
\hline $\begin{array}{l}\text { Occasional use of heroin is not } \\
\text { really dangerous. }\end{array}$ & 0 & 0 & $\begin{array}{l}0 \\
(0 \%)\end{array}$ & $\begin{array}{l}66 \\
(64.1 \%)\end{array}$ & $\begin{array}{l}34 \\
(33 \%)\end{array}$ & $\begin{array}{l}100 \\
(100 \%)\end{array}$ & $1.34 \pm .446$ \\
\hline $\begin{array}{l}\text { Treatment should only be given } \\
\text { to drug addicts who intend to } \\
\text { give up drugs for good }\end{array}$ & $\begin{array}{l}61 \\
(59.2 \%)\end{array}$ & $\begin{array}{l}39 \\
(37.9 \%)\end{array}$ & $\begin{array}{l}0 \\
(0 \%)\end{array}$ & $\begin{array}{l}0 \\
(0 \%)\end{array}$ & $\begin{array}{l}0 \\
(0 \%)\end{array}$ & $\begin{array}{l}100 \\
(100 \%)\end{array}$ & $4.00 \pm .865$ \\
\hline
\end{tabular}




\section{Discussion}

Based on the final data analysis, the prevalence of male' knowledge on drug abuse before the health talk was quite high. Accounting about more than half of the male good knowledge on drug abuse with a sum of $82.03 \%$ whereas only $17.97 \%$ have poor knowledge on drug abuse.

The people group open seemed to have a decent broad attention to normally utilized illicit medications. More than 94 for every penny of respondents revealed that they had known about cannabis, and the larger part of respondents announced having known about bliss (96.3\%), cocaine 94 for every penny of respondents revealed that they had known about cannabis, and the larger part of respondents announced having known about bliss (96.3\%), cocaine (96.4\%) and heroin $(92.3 \%)$. That just about 80 for every penny of respondents viewed every unlawful medication as similarly destructive to one's wellbeing recommends an inability to perceive the diverse different impacts related with various medication composes (Cannabis, Cocaine, Herion and so on). In addition, a generous extent of respondents $(43.5 \%)$ trusted that 'on the off chance that you attempt medicates even once, you are snared', recommending that numerous individuals have unwarranted worries about the idea of the habit procedure as of now comprehended.

\section{Limitations}

This study found many limitations; Time duration was too short. This study was focus only on rural community. Likert scale questionnaire has been used in this study. Data collection was faced lot of issues. The respondents of the study have very careless attitude regarding filling questionnaire.

\section{Conclusion}

To summarize, based on the cross-sectional study that was done, it has been proven that the knowledge, attitude, and beliefs of drug abuse among male is mostly good. The study also showed that there is high prevalence of good knowledge among the male after health talk was given. It is preferable to implement more strategies such as collaboration between policy maker, health workers and religious leaders in order to build a structured education programs and readily accessible to the community.

\section{Acknowledgement}

The first author expresses deep sense of gratitude to Ms. Chanda Jabeen, Lecturer, Lahore school of nursing University of Lahore Pakistan for inspiring and valuable guidance and supervision of this work. She also expresses deepest sense of gratitude to Mr. Muhammed Sabir, Lecturer for their support in English corrections, cooperation, love and prayers, without whom the study would not have been a fruitful one. Authors acknowledge all persons who directly or indirectly helped during study.

\section{References}

Aslam N (2015) Horrendous Situation of Substance Abuse in Pakistan: A BirdÃ $\not \hat{A} \hat{A}$ s Eye View on SocioDemographics. Journal of Alcoholism \& Drug Dependence.

Dos Santos MMLF (2006) Defeating the dragon: Heroin dependence recovery. Doctoral dissertation, University of South Africa.

Kayani AU, King MJ and Fleiter J (2013) A qualitative investigation of drug use among Pakistani road users. Retrieved from: https://eprints.qut.edu.au/65300/1/Kayani_ICADTS_Proc eedings.pdf

Simpson M \& McNulty J (2008) Different needs: women's drug use and treatment in the UK. International Journal of Drug Policy 19(2): 169-175.

South African Community Epidemiology Network on Drug Use. 2010. Monitoring Alcohol and Drug Abuse Treatment Admissions in South Africa. July to December 2009 (Phase 27). Tygerberg: Medical Research Council.

Sungu H (2015) Attitudes towards substance addiction: A study of Turkish University students. Educational Research and Reviews, 10(7), 1015.

United Nations Office on Drugs, Crime (2010) World drug report 2010. United Nations Publications.

UNODC WHO (2013) World Drug Report 2013 By United Nations Office on Drugs and Crime New York: United Nations, 2013 ISBN: 978-92-1-056168-6, 151 pp. Grey literature.

Volkow ND, Fowler JS, Wang G-J, Swanson JM \& Telang F (2007) Dopamine in drug abuse and addiction: results of imaging studies and treatment implications. Archives of neurology 64(11): 1575-1579. 